\section{SOI: 1.1/TAS DOI: 10.15863/TAS \\ International Scientific Journal Theoretical \& Applied Science}

\author{
p-ISSN: 2308-4944 (print) e-ISSN: 2409-0085 (online) \\ Year: $2015 \quad$ Issue: $04 \quad$ Volume: 24
}

Published: 30.04.2015 http://T-Science.org

SECTION 31. Economic research, finance, innovation.
Olga Alexandrovna Tikhomirova Leading marketing manager JSC "Russkiye Samotsvety", Russia olya.russam@gmail.com

Gennady Vasilyevich Kovalenko Associate Professor, Ph.D.,

Peter the Great St.Petersburg Polytechnic University, Russia 7525268@gmail.com

Yulia Anatolyevna Melnikova Deputy General Director for Marketing JSC "Russkiye Samotsvety", Russia ymelnikova@russam.ru

\title{
THE PROBLEM OF SELECTION OF THE NEW ADVERTISING TECHNOLOGIES IN THE JEWELRY INDUSTRY
}

\begin{abstract}
The problem of the selection of the new advertising technologies NEW-AD-TECH by the jewelry sellers is discussed. There are analyzed the reasons of this problem, such as: the lack of terminological clarity in $N E W-A D-T E C H$, specific NEW-AD-TECH features and lack of relevant structured information about the NEW$A D-T E C H$. There is postulated theoretical inconsistency of the existing methods of selecting advertising media to select NEW-AD-TECH because of the fact that the advertising means is only one of the advertising technology's components. The methodology of selection NEW-AD-TECH is based on the methodology Hype Cycle Gartner and takes into account the specifics of the jewelry industry. There are shown the results of the proposed method's testing at the array collected by the authors of structured information describing 79 NEW-AD-TECH. The results of the information analysis are used to derive the conclusions about the use of $5 \mathrm{NEW-AD-TECHs}$ in the advertising of jewelry - "Digital Offers»; "Free Format Projection»; "Social Gaming Ad Networks»; "Social Media Marketing Platforms» and «Eye Tracker».
\end{abstract}

Key words: new advertising technologies, NEW-AD-TECH, advertising management, jewelry, selection, viability, advertising.

Language: Russian

Citation: Tikhomirova OA, Kovalenko GV, Melnikova YA (2015) THE PROBLEM OF SELECTION OF THE NEW ADVERTISING TECHNOLOGIES IN THE JEWELRY INDUSTRY. ISJ Theoretical \& Applied Science 04 (24): 48-56.

Soi: http://s-o-i.org/1.1/TAS*04(24)9 Doi: crossef http://dx.doi.org/10.15863/TAS.2015.04.24.9

УДК 659.1

\section{ПРОБЛЕМА ВЫБОРА НОВЫХ РЕКЛАМНЫХ ТЕХНОЛОГИЙ В ЮВЕЛИРНОЙ ОТРАСЛИ}

Аннотация: Рассматривается проблема выбора новых рекламных технологий (НРТ) продавцами ювелирных изделий. Анализируются причины существования этой проблемы, такие как: отсутствие терминологической определенности в НPT, конкретности в признаках HРТ, отсутствие актуальной структурированной информации о НРТ. Постулируется теоретическая несостоятельность применения существуюших способов выбора рекламных средств для выбора НРТ в силу того, что рекламное средство - это лишь один из компонентов рекламной технологии. Предлагается методика выбора НРТ, основанная на методологии Нуре Cусlе компании Gartner и учитьвающая специфику ювелирной отрасли. Показываются результаты проверки предлагаемой методики на массиве собранной авторами структурированной информации, описывающей 79 НРТ. По результатам анализа информации сделан вывод о перспективности для применения в рекламе ювелирных изделий 5 HPT - «Digital Offers»; «Free Format Projection»; "Social Gaming Ad Networks»; "Social Media Marketing Platforms», "Eye Tracker».

Ключевые слова: новые рекламные технологии, НРТ, рекламный менеджмент, ювелирные изделия, выбор, перспективность, реклама.

\section{Введение}

Ювелирное дело - искусство создания предметов, ориентированных на зрительное восприятие, в них воплощается стремление человека к красоте [1]. Ювелирные изделия ассоциируются с подарками, с праздниками, с приближением момента осуществления мечты, они «овеществляют» отношения и воплощают

ISPC The Combination of Technology \&

Education, Östersund, Sweden 
чувства, ведь ювелирное изделие из золота с бриллиантом доказывает чувства мужчин к любимой женщине лучше любого слова. Ювелирные изделия дарятся или покупаются в преддверии самых важных моментов жизни. В создании ювелирных изделий сохраняются и развиваются многовековые технологии и традиции ювелирного искусства. Ювелирные изделия до сих пор воспринимаются людьми как символ стабильности, успешности и роскоши.

Ювелирные изделия - это особая группа вещей, как правило, имеющих декоративное значение, и часто упоминающихся в многочисленных мифах. Самыми крупными мифами являются: этнический миф - это связь драгоценностей с волшебством и языческой культурой и социально-бытовой миф, связанный с символическими значениями камней, именами, числами, планетами, гороскопами. Связь ювелирных изделий с мифами широко используется в ювелирной практике [2]. Закономерно, что продавцы ювелирных изделий, согласно исследованию компании TNS-global, до сих пор предпочитают рекламировать их в печатной прессе [3], которая позволяет представлять ювелирные украшения в выгодном свете на материальном носителе - бумаге, давая тем самым возможность читателям газет и журналов прикоснуться к этим мифам.

Использование традиционных рекламных технологий пока еще эффективно, однако на сегодняшний день перед продавцами ювелирных изделий достаточно остро стоит вопрос о привлечения внимания молодежной аудитории к своим изделиям. И здесь возникает проблема: как и с помощью каких технологий? Понятно, что, прежде всего, необходимо создать продукт, который нравился бы молодежи - модный, легковесный и недорогой. Даже если принять во внимание, что такой продукт уже создан, то как его показать и про него рассказать молодому поколению, которое предпочитает общаться между собой и с внешним миром с помощью современных коммуникационных технологий?

Как товар, ювелирные изделия не относятся к категориям предметов повседневной необходимости [4; 5; 6], поэтому рынок ювелирных изделий в ходе социальноэкономических кризисов одним из первых испытывает потрясения [4; 5]. В этих условиях и на фоне усиливающейся глобальной конкуренции отечественные продавцы ювелирных изделий, несмотря на весь свой консерватизм в ведении рекламной деятельности, все чаще прибегают к использованию новых рекламных технологий (далее по тексту - НРТ). Примеры тому, хоть и малочисленные, есть - «Виртуальный промоутер» (сеть ювелирных магазинов "Малахит") [7], «Indoor-реклама» (ювелирный завод «Адамант») [8], «Голограмма в витрине» (сеть ювелирных магазинов «Золото 585») [9], мобильное приложение, позволяющее просматривать иллюстрированный каталог ювелирных изделий («Московский ювелирный завод») [10]. Ювелирный завод «Русские самоцветы» продвигает свои изделия на интернет-ресурсах социальных сетей Vkontakte, Twitter, Facebook, Odnoklassniki, создавая и поддерживая имиджевые группы почитателей ювелирных изделий. Также маркетинговой службой предприятия используются мобильные приложения для коммуникаций, такие как WhatsApp и Viber messenger, для оповещения покупателей о предстоящих акциях и новых коллекциях. На предприятии ведётся работа по подготовке к разработке рекламных «вирусных» роликов и рассматривается возможность их распространения через YouTube, что, в настоящее время, не используется отечественными ювелирными компаниями.

Очевидная нераспространенность НРТ в деловой активности отечественных продавцов ювелирных изделий объясняется нерешенностью проблемы выбора НРТ, заключающейся в том, чтобы среди множества рекламных технологий, которые позиционируются их разработчиками как новые, выбрать такие, применение которых позволило бы получить продавцам «эффективность» своей бизнес-деятельности выше, чем по рынку в среднем. Парадоксальным является то, что одной из причин, по которой не применяются НРТ, является боязнь продавцов ювелирных изделий потерять репутацию, но для России данный риск, входящий в десятку значимых рисков мира, не столь значим [11]. Предприниматели России также не считают значительным риском устаревшие технологии, что естественно отражается и на применении НРТ [12]. Проблема выбора обостряется наличием рассмотренных выше особенностей восприятия людьми ювелирных изделий - НРТ, применяемые на рынке ювелирных изделий должны обладать такими характеристиками, которые безусловно отражают эти особенности. Покупается не столько ювелирное изделие, сколько возможность стать причастным к некоему мифу, тайне, и НРТ должны эффективно способствовать именно этому.

В дополнение стоит отметить, что выбор НРТ, как и их анализ, осложняется еще и тем, что некоторые НРТ проблематично описать на русском языке, в том числе из-за иноязыковой оригинальности терминов.

Неудивительно, что продавцы ювелирных изделий осуществляют выбор НРТ, как правило, 
путем проб и ошибок, изначально становясь на этот путь скорее, следуя общей моде и трендам, чем руководствуясь результатам научного анализа ситуации. Одной из причин такому положению дел, является отсутствие единства в понимании и строгом определении терминов «рекламная технология», «новая рекламная технология».

Термин «рекламной технологии» раскрывают многие авторы: О.И. Зотова, Е.В. Латышева, А.А. Скопин [13; 14, С.6; 15, С.5-6]. По мнению Е.В. Латышевой, технология в рекламной деятельности это поэтапный процесс создания рекламного продукта от зарождения идеи до ее воплощения и средства (подходы), применяемые для реализации этой идеи [14, С.6]. О.И. Зотова определяет практическую рекламную технологию, как отработанную опытом совокупность процессов и операций по созданию определенного вида рекламного средства [13]. А.А. Скопин пишет: «Предметом исследования и разработки в технологии производства рекламного продукта являются технологические процессы (начиная с возникновения идеи до ее материального воплощения в рекламные тексты, плакаты, аудио-, видеоролики и т.п.), способы обработки различных материалов и поверхностей, методы изготовления и сборки типовых и уникальных рекламных конструкций, управление качеством рекламного продукта, стандартизация и т.п.» [15, C.5-6].

Представляется, что разночтение в определении термина «рекламная технология» объясняется существенной недооценкой роли рекламных технологий, которую она играет в современном рекламном бизнесе. Например, доктор социологических наук И.А. Полуэхтова, в своей работе подробно и наглядно описывает структуру рекламной индустрии, показывая разных участников, вовлеченных в рекламный процесс [16]. Однако, в ее схеме не представлены поставщики рекламных технологий, в том числе новых, хотя согласно общепризнанной классической методике «Пять сил Портера», поставщики - это неотъемлемый и ключевой элемент рынка. То же самое можно сказать о структуре рекламного рынка, представленной А.А. Романовым и А.В. Панько [17, С.45]. Аналогично, К.В. Антипов изображает элементы рекламного процесса, никак не рассматривая поставщиков рекламных технологий как участников рыночных отношений [18, С.100].

Логичным следствием неопределенности с терминологией является отсутствие научнообоснованных классификаций рекламных технологий. Большинством авторов предлагаются, как правило, классификации рекламных средств, что достаточно странно, так как рекламное средство - это всего лишь компонент рекламной технологии. Например, О.В. Воронкова, К.В. Завражина, Р.Р. Толстяков выделяют основные средства рекламы согласно Международной Рекламной Ассоциации АКАР: реклама в прессе, печатная реклама, аудиовизуальная реклама, радиореклама, телевизионная реклама, рекламные сувениры, наружная реклама, Интернет-реклама, выставки и ярмарки (PR), почтовая реклама (direct-mail) [19, C. 51]. А.В. Катернюк классифицирует рекламные средства по каналам распространения информации: печатная реклама (рекламнокоммерческие листовки, каталоги, проспекты, буклеты, брошюры и т.д.), газетно-журнальная реклама, радиореклама, телереклама, кинореклама, наружная реклама, реклама на транспорте, прямая почтовая реклама, реклама «в каждый дом», выставки, специальные виды рекламы (реклама в посылочной торговле, реклама магазина, финансовая реклама и т.д.), прочие виды рекламы (сувенирная реклама, имиджевая и т.д.) [20, С.32]. А.Н. Мудров выделяет следующие рекламные средства по типам рекламоносителей: реклама в прессе, ТВреклама, радиореклама, наружная (уличная) реклама, транспортная, кинореклама, компьютерная реклама (реклама в Интернете, реклама, передающаяся по мобильной связи), интерьерная, магазинная (реклама в местах продаж или розничная), директ-мейл (прямая почтовая реклама), печатная, сувенирная, нетрадиционная реклама [21, С.48].

Вряд ли проблему выбора НРТ можно решить, используя имеющиеся классификации рекламных средств и способы их выбора, даже такие широко применяемые как способ К.В. Антипова [18, С.220]. По отдельному компоненту системы проблематично выбрать систему, адекватную поставленным задачам. Логично, что авторы, пишущие о НРТ, как правило, не дают ни количественной оценки НРТ, ни оценки возможности их применения и, поэтому, обычно, отделываются общими фразами, не имеющими практического смысла: «Сегодня помимо традиционных методов воздействия на конечного потребителя, существуют также методы с использованием инновационных технологий.» [22] «...помимо традиционных рекламных методов воздействия на конечного потребителя применяют также методы с использованием инновационных технологий...» $[23$, C.14 $]$ «Инновационные технологии активно внедряются в рекламный инструментарий XXI века. Инновации используются в различных областях рекламы, как в ее традиционных форматах, так и в нестандартных рекламных коммуникациях.» [24] «Инновационные 
рекламные технологии эффективнее, масштабнее по сравнению с традиционными видами рекламы.» [25] «На сегодня кроме традиционных методов рекламы, воздействующих на потребителя, есть также методы, использующие инновационные технологии.» [26]

Решение проблемы выбора НРТ может заключаться в разработке методики выбора НРТ на основе методологии Нуре Cycle [27], которая активно применяется с 1995 года компанией Gartner для оценки перспектив развития и востребованности новых технологий, как правило, связанных с IT-индустрией. Методология Нуре Cycle основана на визуализации зрелости и распространенности технологий. Она дает возможность получить представление о том, как технология или приложение будет развиваться с течением времени, производя «шум» от внедрения применения технологии, для того, чтобы управлять её использованием в контексте конкретных бизнес-целей [28].

Что касается характеристик НРТ, то авторы статьи в целом разделяют мнение, опубликованное в [25], что НРТ присущи такие характеристики как необычность носителя, широта охвата при минимальных финансовых издержках, мобильность, персонализация, учет эмоций, неизбежность просмотра, ощущение дополненной реальности, эффект присутствия. Однако, исходя из особенностей восприятия людьми ювелирных изделий, наличие «необычности носителя» в характеристике НРТ для рекламы ювелирных изделий представляется весьма дискуссионным. В случае же с неизбежностью просмотра речь идет о навязывании рекламной информации потребителю против его воли, что противоречит элементарным этическим нормам.

К специфическим признакам (особенностям) НРТ в ювелирной отрасли можно отнести: широта охвата при минимальных финансовых издержках, мобильность, персонализация, учет эмоций, ощущение дополненной реальности, эффект присутствия.

\section{Методическая часть}

В методике выбора НРТ, разработанной авторами статьи (см. рис.1), предлагается действовать исходя их трех условий:

1. визуализация траектории развития НРТ по методологии Нуре Cycle;

2. оценка поведения этих траекторий в условиях экономических кризисов в конкретные периоды;

3. учет применимости выявленных НРТ к специфике и особенностям восприятия людьми ювелирных изделий.
На этапе визуализации сначала проводится выявление и мониторинг НРТ, для этого используются поисковые запросы в системах Интернет: Google, Yandex, Bing. Формируются запросы: новая рекламная технология, инновационная рекламная технология, инновационная реклама. Информация о НРТ выявляется также на сайтах рекламных агентств и фирм, предлагающих НРТ, а также компаний, исследующих рынок НРТ. Фактически речь идет о создании на этом этапе постоянно пополняемой и актуализируемой базе данных рекламных технологий, в том числе НРТ.

На основании имеющихся и полученных новых данных проводится ранжирование по количеству упоминаний названия НРТ в поисковых запросах в Сети, используется поисковая система Google. Количество запросов отражается в списке выявленных НРТ. Далее отбираются НРТ, у которых наибольшее количество упоминаний в Сети. Одновременно, группа экспертов в области продвижения ювелирных изделий отбирает из списка выявленных НРТ наиболее эффективные с их точки зрения, на основании личного опыта работы в рекламной деятельности. Далее перечень наиболее упоминаемых в Интернете НРТ сопоставляется с перечнем НРТ, отобранных экспертами.

Перечень НРТ по популярности упоминаний в Интернете, совпавший с перечнем лучших НРТ, выбранных экспертами, подвергается оценке в первую очередь. Далее оцениваются НРТ, выбранные экспертами, но не лидирующие по количеству упоминаний. Приоритетными для применения будут являться НРТ, выбранные экспертами.

Этап визуализации завершается составлением графиков Нуре Cycle, характеризующих распределения количества упоминаний той или иной НРТ по годам. Сплошная линия на графике - кривая частоты встречаемости наименования НРТ в печатных и интернет-изданиях в период 1995-2013гг (по оси абсцисс - года, по оси ординат - частота встречаемости).

Полученные траектории Нуре Cycle анализируются и оцениваются с позиций: чувствительности траекторий Нype Cycle выбранных НРТ на устойчивость к событиям краха «доткомов» 2000г. и кризиса 2008г., а также неизменности используемой в открытых источниках терминологии при описании конкретной НРТ. 


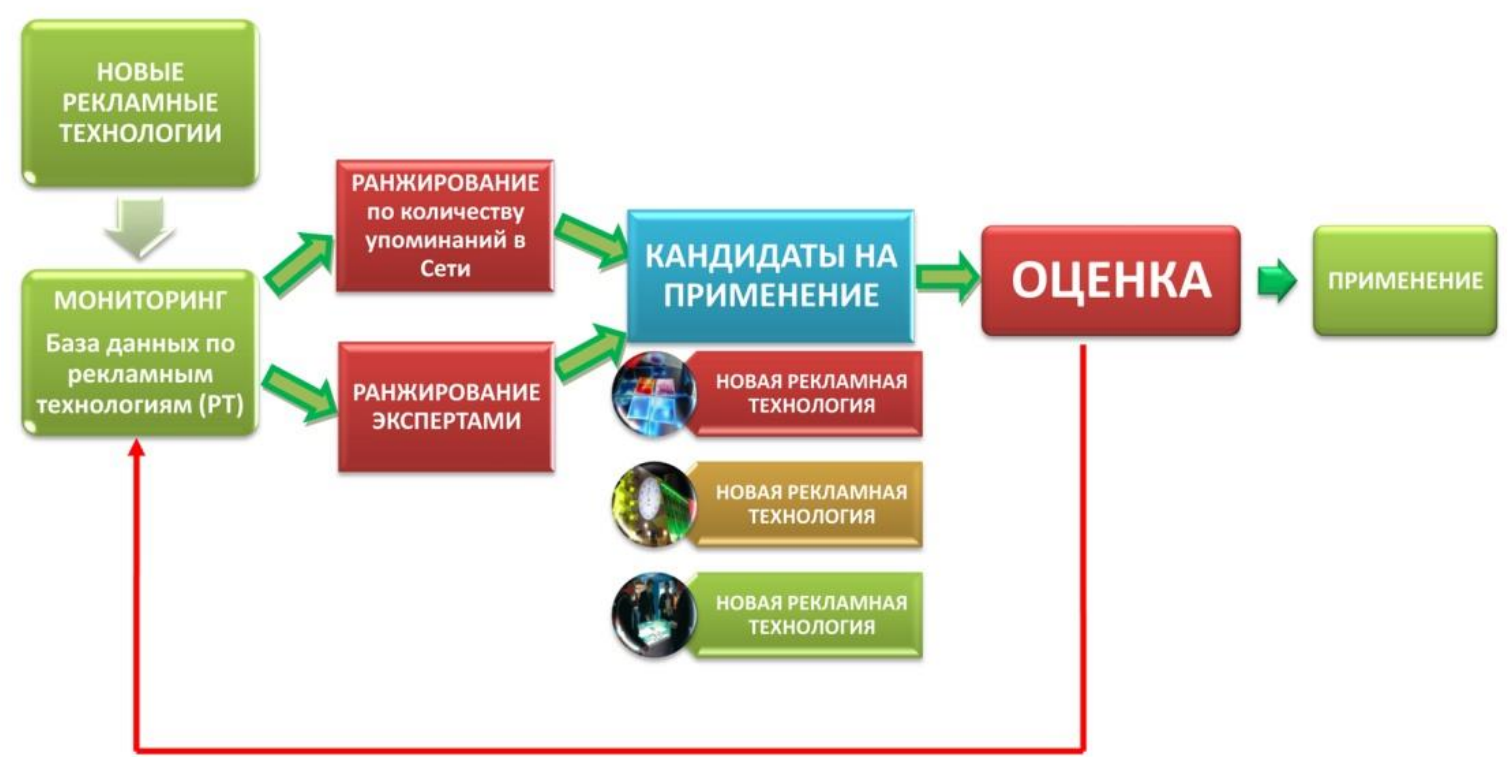

Рисунок 1 - Блок-схема выбора новых рекламных технологий.

\section{Экспериментальная часть}

Всего по состоянию на ноябрь 2014 года авторами статьи было выявлено 79 НРТ.

В силу объективных временных ограничений Нype Cycles были визуализированы авторами для 10 НРТ наиболее цитируемых в сети Интернет и 10 НРТ выбранных экспертами ювелирного предприятия. В первую очередь оценке подверглись 4 НРТ, совпавшие по популярности упоминаний в сети и по мнению экспертов.

Как видно из соответствующего графика, представленного на рис. 2, HРT «Digital Offers», согласно классификации Gartner, развивается и находится на стадии «Пик ожиданий». Кризисы оказали незначительное влияние на развитие данной технологии, поэтому эту технологию можно рекомендовать для применения в рекламной деятельности продавцов ювелирных изделий.

Графическую кривую развития НРТ «RealTime Marketing» можно оценивать аналогично развитию кривой технологии «Digital Offers» данная технология развивается и находится на стадии «Пик ожиданий», кризисы оказали незначительное влияние на развитие данной технологии, поэтому эту технологию можно рекомендовать для применения в рекламной деятельности продавцов ювелирных изделий.

HPT «Social Gaming Ad Networks» до кризиса 2008 года развивалась невысокими темпами, однако в последние годы наблюдается резкий скачок в еe развитии. Согласно классификации Gartner данная технология находится на стадии «Пик ожиданий». Тренд развития можно определить, как устойчиво нарастающий. Эту технологию можно рекомендовать для применения в рекламной деятельности продавцов ювелирных изделий.

HPT «Video-in-Print» - после каждого кризиса наблюдается падение интереса к ней, иными словами, технология развивается, когда экономическая ситуация стабильна. Наличие стабильности сомнительно в среднесрочной экономической перспективе, поэтому из четырёх НРТ, графика развития которых представлена на рис. 2, данную технологию вряд ли можно рекомендовать для применения в рекламной деятельности продавцов ювелирных изделий. 

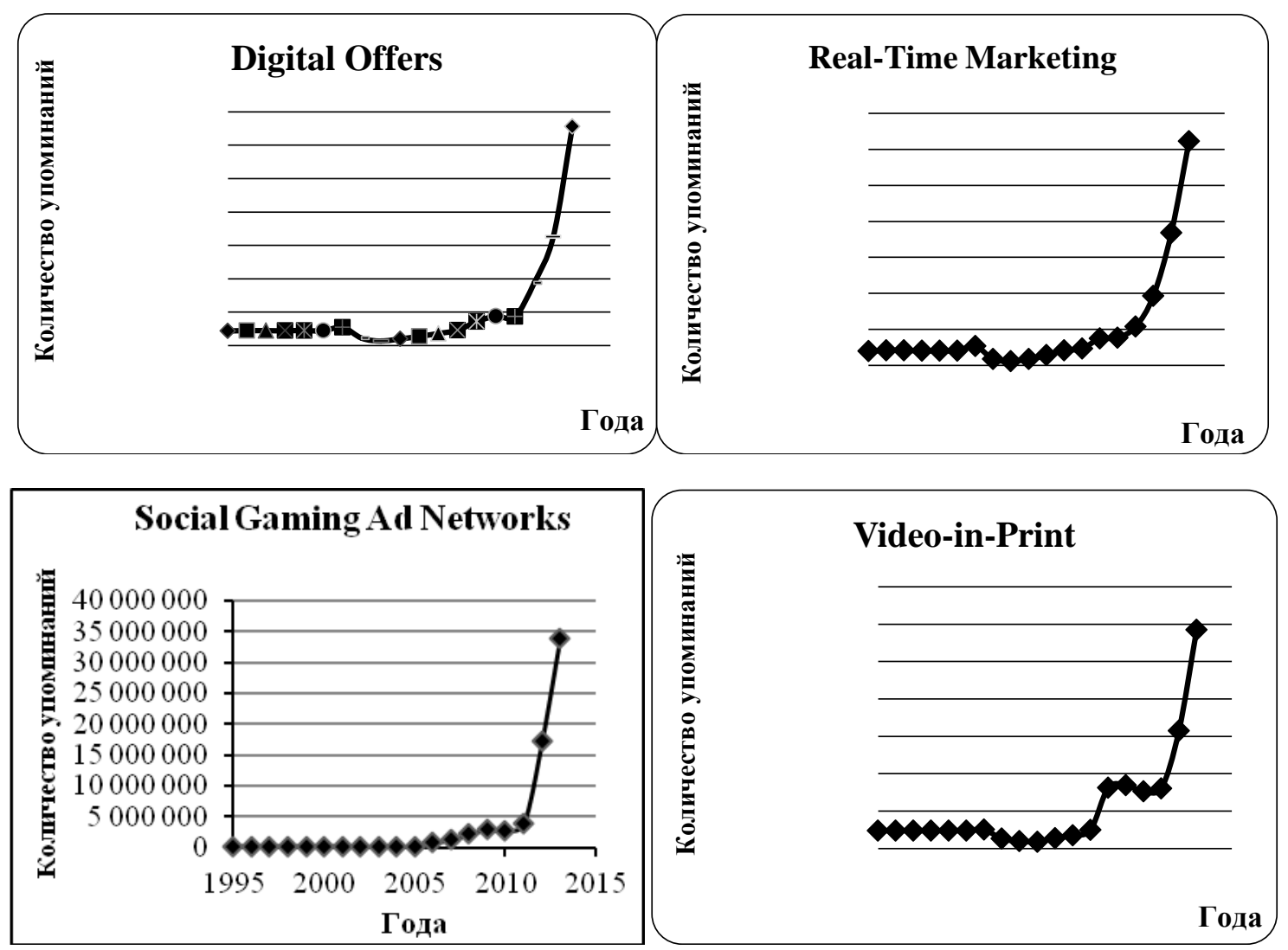

Рисунок 2 - Визуализация распределения количества упоминаний словосочетаний «Digital Offers», «Real-Time Marketing», «Social Gaming Ad Networks», «Video-in-Print» в поисковой системе «Google» за период с 1995 по 2013 гг.

На рис. 3 представлена визуализация распределения количества упоминаний словосочетаний «Еуe Tracker», «Free Format Projection», «Social Media Marketing Platforms», «2D Bar Code Marketing», «Виртуальный промоутер», «Cloud Advertising» - это НРТ, которые были выбраны экспертами, хотя эти технологии и не лидируют по количеству упоминаний в Сети.

HРТ «Еуe Tracker», на развитие данной технологии повлиял кризис 2008 года, и оценивать ее можно так: с одной стороны, можно говорить, что она чувствительна к кризисам, а с другой стороны, есть вероятность, что данная технология пересекла стадию «Плато продуктивности», не свалившись в «Пропасть разочарований» и уже вышла на стадию вторичного «Пика ожиданий» Эту технологию можно рекомендовать для применения в рекламной деятельности продавцов ювелирных изделий.

HPT «Social Media Marketing Platforms» находится на стадии «Пик ожиданий», график, представленный на рис. 3, отражает ее явно взрывной рост. Мы видим непрерывную динамику развития этой технологии, на которую не оказывают воздействия кризисы. Данную технологию можно рассматривать, как перспективную.

HPT «2D Bar Code Marketing» устойчиво развивается, однако, наблюдаются провалы и торможения в развитии после кризисов. Но сама идея 2D кодирования устойчива, поэтому возможно имеет смысл более тщательно рассмотреть экономическую характеристику данной технологии и понаблюдать за дальнейшим развитием технологии.

HРТ «Free Format Projection» остановила своё развитие после кризиса «доткомов», но далее, несмотря на кризис 2008 года, продолжила развиваться. По этой рекламной технологии также имеется устойчивость в терминологии. Думается, имеет смысл отметить эту технологию, как перспективную. 

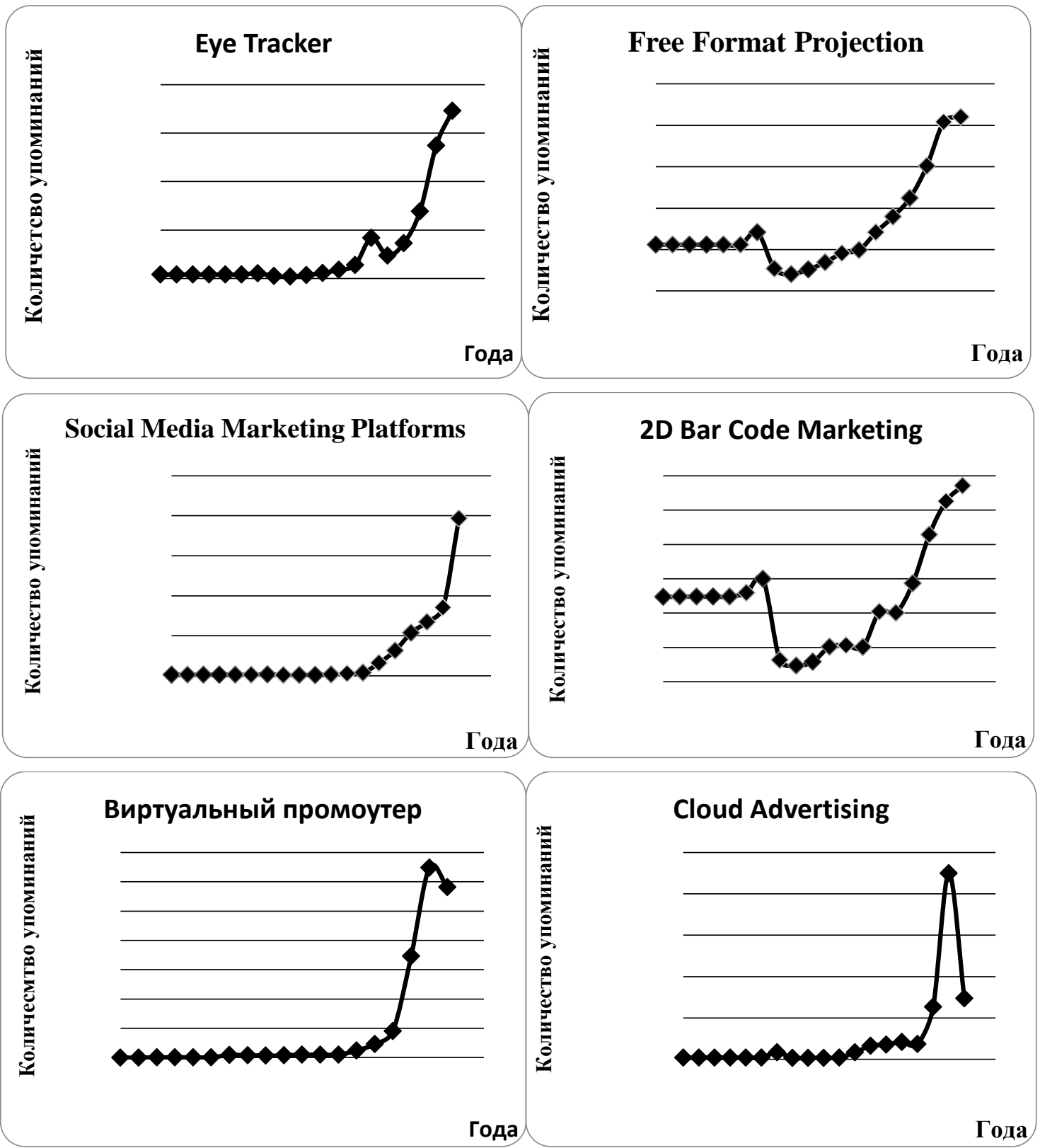

Рисунок 3 - Визуализация распределения количества упоминаний словосочетаний «Eye Tracker», «Free Format Projection», «Social Media Marketing Platforms», «2D Bar Code Marketing» «Виртуальный промоутер», «Cloud Advertising» в поисковой системе «Gоogle» за период с 1995 по 2013 гг.

Следующие две технологии имеют схожие графики. НРТ «Виртуальный промоутер» после кризиса 2008 года стала стремительно развиваться, терминология по ней устойчива, однако с 2012 года рост сменился спадом и, согласно классификации Gartner, данная рекламная технология находится на «Склоне разочарований». HPT «Cloud Advertising» согласно классификации Gartner также находится на «Склоне разочарований», после краха «доткомов» были определенные надежды на данную технологию, но они не реализовались.

Результаты

В результате оценки НРТ по перспективности для продавцов ювелирных изделий: из семидесяти девяти НРТ перспективны к рассмотрению одиннадцать, необходимо дополнительно понаблюдать за тремя технологиями, не стоит применять две технологии, а для практического применения может быть рекомендовано пять технологии. Для 
применения в рекламной деятельности продавцов ювелирных изделий можно рекомендовать следующие НРТ: «Digital Offers»; «Free Format Projection»; «Social Gaming Ad Networks»; «Social Media Marketing Platforms», «Eye Tracker».

Так как понятие «Digital Offers» достаточно широкое, то, как представителя этой технологии, можно выделить такую новинку как мульти-тач витрина.

Игры в социальных сетях Интернета действительно достойны внимания со стороны продавцов ювелирных изделий, так как, применяя данную технологию, они получают возможность взаимодействия с потенциальным покупателем, который не равнодушен к товару и в момент восприятия рекламы находится в расслабленном состоянии, ведь многие люди погружаются в виртуальные миры с целью уйти от повседневной рутины и проблем, спрятаться за широкими спинами своих виртуальных героев. Если учесть, что виртуальная реальность может влиять непосредственно на органы чувств, побуждая человека продуцировать гормоны счастья [29], то данный аспект рекламы в играх явно способствует установлению положительного контакта между продавцом ювелирных изделий и потребителем. Визуальная кривая развития НРТ «Social Media Marketing Platforms» аналогична указанной выше кривой количества упоминаний технологии «Social Gaming Ad Networks». НРТ «Social Media Marketing Platforms» предоставляет сотрудникам рекламных служб продавцов ювелирных изделий возможность безошибочно выделять свою целевую аудиторию в соответствии с такими критериями, как пол, возраст, место проживания, род деятельности, круг интересов и многими другими. Благодаря этому реклама гарантированно достигает непосредственно своего адресата и оказывается максимально рентабельной из-за высокого уровня конверсии [30], а как рассматривалось выше, персонализация является одной из особенностей НРТ применительно к рекламе ювелирных изделий.

HPT «Free Format Projection» создает ощущение присутствия персонажей или объектов в натуральную величину за счет особой обработки изображения. Однако, в силу относительной дороговизны данной рекламной технологии, а также специфики ювелирной отрасли, применение этой технологии ограничено профильными выставками.

HРT «Eуe Tracker» уникальна тем, что её можно применять как в виртуальной реальности, так и в реальном магазине.

\section{Дискуссия}

Как уже было отмечено, в ходе проведения исследования о НРТ в ювелирной отрасли, одним из авторов настоящей статьи был создан справочник (база данных) с описанием 79 НРТ. Однако, авторы статьи сознают, что состав данного списка является предметом для дискуссии и не может быть стабильным - в найденных рекламных технологиях некоторые технологии входят в состав других, некоторые представляют собой набор других технологий, многие из указанных в справочнике технологий взаимопересекаются, многие НРТ ещё только зарождаются и поэтому еще неизвестны в России.

\section{References:}

1. (2015) Yuvelirnye tovary [Electronic resource]. - Available: http://uvelir.info/articles/15992/ (Accessed: 13.03.2015).

2. Morozova O (2015) Yuvelirnaya reklama: chto, komu i kak [Electronic resource]. - Available: http://www.posm.ru/library/articles.php?article id=18 (Accessed: 13.03.2015).

3. (2015) Analiz rynka reklamy yuvelirnykh izdely i chasov [Electronic resource]. Available: http://www.tnsglobal.ru/services/monitoring/advertising/jewel ery (Accessed: 13.03.2015).

4. Babkova KY (2015) Osnovnye napravleniya razvitiya sovremennykh formatov roznichnoy yuvelirnoy torgovli [Electronic resource] /
ISPC The Combination of Technology \& Education, Östersund, Sweden
K.Yu. Babkova, O.S. Zybin // Nauchny zhurnal NIU ITMO. Seriya «Ekonomika i ekologichesky menedzhment». - Available: http://economics.ihbt.ifmo.ru/file/article/6739.p df (Accessed: 13.03.2015).

5. (2015) Marketing $\mathrm{v}$ yuvelirnoy oblasti [Electronic resource]. - Available: http://jewellir.ru/article/366 $\quad$ (Accessed: 13.03.2015).

6. (2015) Kak otkryt yuvelirny magazin [Electronic resource]. - Available: http://uvelir.info/articles/26637/ (Accessed: 13.03.2015).

7. (2015) Virtualnye promoutery [Electronic resource].
Available: 
http://www.gefestcapital.ru/portfoliovpromo.html (Accessed: 13.03.2015).

8. (2013) «Nemoy prodavets», ili Yeshche odin sposob prevratit posetitelya $\mathrm{v}$ pokupatelya [Text] // Navigator yuvelirnoy torgovli. - 2013. - № 9(127). - pp. 24-27.

9. (2015) Gologramma v reklame: vitrina magazine [Electronic resource]. - Available: http://vidoz.pp.ua/video/-2qDYzmbiXV.html (Accessed: 13.03.2015).

10. (2015) MYuZ: Yuvelirnye izdeliya [Electronic resource]. $\quad-\quad$ Available: https://play.google.com/store/apps/details?id=ru .mjf\&hl=ru (Accessed: 06.04.2015).

11. Kovalenko GV (2014) Specifics of business risks perception in Russia. ISJ Theoretical \& Applied Science 9 (17): 174-179. Soi: http://so-i.org/1.1/TAS*09(17)30 doi: http://dx.doi.org/10.15863/TAS.2014.09.17.30 (Accessed: 21.03.2015).

12. Kovalenko GV, Kolosova OV (2014) Innovation projects managers perception and assessment of risks. ISJ Theoretical \& Applied Science 2 (10), pp.156-161. Soi: http://s-oi.org/1.1/TAS*02(10)27 doi: http://dx.doi.org/10.15863/TAS.2014.02.10.27 (Accessed: 21.03.2015).

13. Zotova OI (2010) Reklamnye tekhnologii kak sistemoobrazuyushchaya osnova marketinga prodvizheniya [Text] / O. I. Zotova. / Izvestiya Tulskogo gosudarstvennogo universiteta. -2010. - № 1. - Part 2. - pp. 252 - 259 .

14. Latysheva YV (2009) Razrabotka i tekhnologiya proizvodstva reklamnogo produkta (kulturologichesky i sotsiolingvistichesky aspekty): uchebnoye posobiye [Text] / Ye.V. Latysheva. - Tomsk: Izd-vo Tomskogo politekhnicheskogo universiteta, 2009. - $118 \mathrm{p}$.

15. Skopin AA (2009) Razrabotka i tekhnologii proizvodstva reklamnogo produkta: Uchebnometodicheskoye posobiye [Text] / A.A.Skopin. - Yaroslavl: Remder, 2009. - 118 p.

16. (2015) Sotsiologiya $v$ reklamnoy deyatelnosti [Electronic resource]. - Available: http://www.myshared.ru/slide/404877/

(Accessed: 13.03.2015).

17. (2006) Marketingovye kommunikatsii [Text] / A.A. Romanov, A.V. Panko. - M.: Eksmo, 2006. - 432 p. - (Pritselny marketing).

18. Antipov KV (2009) Osnovy reklamy: Uchebnik [Text] / K. V. Antipov. - M.: Izdatelsko-torgovaya korporatsiya «Dashkov i $\mathrm{K}^{\circ} \gg, 2009$. - $328 \mathrm{p}$.

19. (2009) Marketing: uchebnoye posobiye [Text] / O.V. Voronkova, K.V. Zavrazhina, R.R.
Tolstyakov i dr.; pod obshch. red. O.V. Voronkovoy. - Tambov : Izd-vo Tamb. gos. tekhn. un-ta, 2009. - 120 p.

20. Katernyuk AV (2001) Reklamnye tekhnologii. Kommercheskaya reklama: ucheb. posobiye dlya vuzov [Text] / A.V. Katernyuk; soavtor O.G. Marchenko. - Rostov na Donu: Feniks, 2001. - $130 \mathrm{p}$.

21. Mudrov AN (2008) Osnovy reklamy: uchebnik [Text] / A.N. Mudrov. - M.: Ekonomist, 2005.319p.: il. Osnovy reklamy : uchebnik [Text] / A. N. Mudrov. - 2-e izd.. pererab. i dop. Moscow: Magistr, 2008. - 397 p.

22. Berezina Y (2009) Innovatsionnye reklamnye tekhnologii [Text] / Berezina Yu. // Prodvizheniye Prodovolstviya. Prod\&Prod. 2009. - №10-11(12-13).

23. Zhavoronkova OR (2011) Sovremennye innovatsionnye tekhnologii $\mathrm{v}$ reklame [Text] / O.R.Zhavoronkova // Ekonomika Kryma. 2011. - № 4 (37) - pp. 14-17.

24. Egina Y (2009) Teoriya reklamy: Innovatsii v reklame [Text] / Ye.Egina. Materialy mezhdunarodnoy konferentsii. - Moscow, 2009. - pp.437-439.

25. (2015) Ispolzovaniye innovatsionnykh tekhnology v reklame [Electronic resource]. Available:

http://www.economy.nayka.com.ua/?op=1\&z= 1259 (Accessed: 13.03.2015).

26. (2015) Innovatsii v internet-reklame. Tekhnologiya Videoclick [Electronic resource].

Available:

http://www.docme.ru/doc/537747/innovacii-vinternet-reklame.-tehnologiya-videoclick (Accessed: 13.03.2015).

27. (2015) Hype Cycle (Tsikl zrelosti tekhnology Gartner) [Electronic resource]. - Available: http://tadviser.ru/a/114590 (Accessed: 13.03.2015)

28. (2015) Hype Cycles [Electronic resource]. Available:

http://www.gartner.com/technology/research/m ethodologies/hype-cycles.jsp (Accessed: 13.03.2015).

29. (2015) Virtualnaya realnost [Electronic resource]. $\quad-\quad$ Available: http://www.molomo.ru/myth/virtual_reality.htm 1 (Accessed: 13.03.2015).

30. (2015) Social Media Marketing: osnovnye osobennosti i perspektivy [Electronic resource]. - $\quad$ Available: http://www.vadimgalkin.pp.ru/prodvizhenie/soc ial-media-marketing/ (Accessed: 13.03.2015). 